\title{
Analysis of Melanoma in African American Patients in the United States
}

\author{
DANIEL BOCZAR ${ }^{1}$, DAVID J. RESTREPO ${ }^{1}$, ANDREA SISTI ${ }^{1}$, MARIA T. HUAYLLANI ${ }^{1}$, \\ HUMZA Y. SALEEM ${ }^{2}$, XIAONA LU ${ }^{3}$, GABRIELA CINOTTO ${ }^{1}$, \\ OSCAR J. MANRIQUE ${ }^{4}$, AARON C. SPAULDING ${ }^{5}$ and ANTONIO J. FORTE ${ }^{1}$ \\ ${ }^{1}$ Division of Plastic Surgery, Mayo Clinic, Jacksonville, FL, U.S.A.; \\ ${ }^{2}$ Department of Surgery, Mayo Clinic, Jacksonville, FL, U.S.A.; \\ ${ }^{3}$ Division of Plastic and Reconstructive Surgery, Yale School of Medicine, New Haven, CT, U.S.A.; \\ ${ }^{4}$ Division of Plastic Surgery, Mayo Clinic, Rochester, MN, U.S.A.; \\ ${ }^{5}$ Robert D. and Patricia E. Kern Center for the Science of Health Care Delivery, \\ Mayo Clinic, Jacksonville, FL, U.S.A.
}

\begin{abstract}
Background/Aim: To characterize the demographics, tumor staging and treatment of African American (AA) patients diagnosed with melanoma in the United States. Patients and Methods: The National Cancer Database was used to extrapolate data from patients with melanoma between January 1, 2004, and December 31, 2015. The patients were then further divided based on ethnicity (AAs vs. Caucasians) to compare patient efficacy of treatment. Results: The mean time for AA patients to receive treatment was 20.37 days compared with 11.25 days for Caucasians $(p<0.001)$, while time to surgery was 38.86 days compared to 31.12 days for Caucasians $(p<0.001)$. Moreover, AA race was a predictor of American Joint Committee on Cancer stage greater than II, tumor diagnosed at autopsy, presence of ulceration, and distribution in the extremities. Conclusion: AA patients with melanoma are more likely to have worse tumor staging, treatment delay, treatment at an Integrated Cancer Program, and diagnosis at autopsy.
\end{abstract}

African American's (AA) have a decreased likelihood of developing melanoma when compared to other ethnicities due to the protective action of melanin (1). The incidence of melanoma amongst AAs is 1 to 1.2 per 100,000 (2). However, melanoma in AA patients is frequently diagnosed at an advanced stage due to the difficulty in differentiating between skin tone and cancer combined with lower

Correspondence to: Antonio Jorge Forte, MD, Ph.D., Mayo Clinic Florida, 4500 San Pablo Road, Jacksonville, FL 32224, U.S.A. Tel: +1 9049532073, e-mail: ajvforte@yahoo.com.br

Key Words: Melanoma, cancer, skin cancer, tumor, African American, disparities, minorities. socioeconomic levels $(3,4)$. In addition, melanoma survival is lower in AA patients undergoing surgical treatment compared to all other ethnicities (5). Etiologies of these disparities are difficult to assess and poorly understood (15). Treatment disparity in minority populations is a debated topic that deserves attention from the scientific community (6). In this study, we aimed to assess the difference in melanoma characteristics, patient population, tumor staging and treatment in AA compared to the Caucasian population. Furthermore, we speculated that significant differences exist between the two populations.

\section{Patients and Methods}

This study was considered nonregulated by the institutional review board. The National Cancer Database (NCDB), an initiative driven by the American Cancer Society and the American College of Surgeons' Commission on Cancer that registers $70 \%$ of all cancers diagnosed in the USA, was used to extrapolate data $(7,8)$.

Eligible patients were identified according to the NCDB's variable "Race". Data were extracted for all patients diagnosed with melanoma between January 1, 2004, and December 31, 2015. The cohort was then split into two groups based on race: 1) AA or 2) Caucasian. Patients identified with others races, such as Asian or Native American, were excluded as this analysis focused on the comparison between AA patients and Caucasian patients, the largest cohort of patients with melanoma.

Data was extracted on patient demographics, facility/treatment type, and tumor characteristics. Patients demographics included age, sex, insurance (Uninsured, Private, Medicaid, Medicare, Other Government, Unknown), and population density (Metro, Urban, Rural, Unknown). Facility/treatment characteristics included facility type, region, days between diagnosis and treatment, and days to discharge (after most-definitive surgical procedure). Tumor characteristics included invasive behavior, Breslow depth, American Joint Committee on Cancer (AJCC) stage, and presence of ulceration. 
Table I. Patient demographic and clinical data by race.

\begin{tabular}{|c|c|c|c|c|c|}
\hline \multirow[b]{2}{*}{ Variable } & \multicolumn{2}{|c|}{ Caucasians } & \multicolumn{2}{|c|}{ African Americans } & \multirow[b]{2}{*}{$p$-Value } \\
\hline & No & $\%$ & No & $\%$ & \\
\hline Total & 510,847 & $94.4 \%$ & 3008 & $0.6 \%$ & \\
\hline Mean age (SD) & 61.57 & 16.102 & 60.92 & 16.992 & 0.001 \\
\hline Median age & 63 & & 62 & & \\
\hline Age group & & & & & 0.312 \\
\hline $0-49$ & 114,452 & $22.4 \%$ & 696 & $23.1 \%$ & \\
\hline $50-59$ & 101,347 & $19.8 \%$ & 628 & $20.9 \%$ & \\
\hline $60-69$ & 118,820 & $23.3 \%$ & 660 & $21.9 \%$ & \\
\hline $70-79$ & 104,517 & $20.5 \%$ & 606 & $20.1 \%$ & \\
\hline $80+$ & 71,711 & $14.0 \%$ & 418 & $13.9 \%$ & \\
\hline Gender & & & & & $<0.001$ \\
\hline Male & 293,860 & $57.5 \%$ & 1,276 & $42.4 \%$ & \\
\hline Female & 216,987 & $42.5 \%$ & 1,732 & $57.6 \%$ & \\
\hline Insurance status & & & & & $<0.001$ \\
\hline Not insured & 10,739 & $2.1 \%$ & 163 & $5.4 \%$ & \\
\hline Private insurance & 264,358 & $51.7 \%$ & 1,228 & $40.8 \%$ & \\
\hline Medicaid & 11,495 & $2.3 \%$ & 265 & $8.8 \%$ & \\
\hline Medicare & 207,582 & $40.6 \%$ & 1,229 & $40.9 \%$ & \\
\hline Other government & 5,201 & $1.0 \%$ & 42 & $1.4 \%$ & \\
\hline Insurance status unknown & 11,472 & $2.2 \%$ & 81 & $2.7 \%$ & \\
\hline Facility type & & & & & $<0.001$ \\
\hline Community cancer program & $30,153.00$ & $5.9 \%$ & 168.00 & $5.6 \%$ & \\
\hline Comprehensive community cancer program & $168,401.00$ & $33.0 \%$ & 748.00 & $24.9 \%$ & \\
\hline Academic/Research program & $218,402.00$ & $42.8 \%$ & $1,380.00$ & $45.9 \%$ & \\
\hline Integrated network cancer program & $41,554.00$ & $8.1 \%$ & 371.00 & $12.3 \%$ & \\
\hline Missing & $52,337.00$ & $10.2 \%$ & 341.00 & $11.3 \%$ & \\
\hline
\end{tabular}

$p$-Value was estimated by Chi-square or T-test.

Patient demographics, facility/treatment type, and tumor characteristics were described and analyzed using $\chi^{2}$ or $t$-test, as appropriate. Multivariate analyses were performed using logistic regression models to assess independent associations, adjusting for confounders. Multiple analyses were conducted, setting as the outcome variable each facility type, tumor behavior, AJCC tumor stage and diagnosis at autopsy, and predicted variable of AA patients compared to Caucasians. The significance level was set at $p<0.05$. Statistical analysis was done using SPSS 25.0 statistical software (SPSS Inc.).

\section{Results}

A total of 513,855 patients met the inclusion criteria. The analyzed cohort included 3,008 AA patients $(0.6 \%)$ and 510,847 Caucasians (99.4\%). Table I outlines patient demographics and facility characteristics by tumor location. Melanoma in AA patients was significantly more prevalent amongst women and patients who were uninsured or insured by Medicaid $(p<0.001)$. AA patients were found to receive treatment in Comprehensive Community Cancer Programs less frequently compared to Caucasian patients (Table I).

Tumor characteristics and treatment type separated by race are presented in Table II. Invasive behavior, Breslow depth greater than $1.01 \mathrm{~mm}$, and tumor stage II to IV were more prevalent in AA patients $(p<0.001)$. Furthermore, AA patients had a higher frequency of melanomas on the extremities and decreased incidence on the head and neck and trunk $(p<0.001)$. AA patients had a longer time between diagnosis and treatment and between surgery and discharge $(p<0.001)$.

Using multivariate analysis (Table III), we noticed that AA patients had increased odds for melanoma with ulceration $(\mathrm{OR}=1.687 ; 95 \% \mathrm{CI}=1.514-1.880 ; p<0.001)$, located in the extremities $(\mathrm{OR}=3.609 ; 95 \% \mathrm{CI}=3.298-3.949 ; p<0.001)$, stage II $(\mathrm{OR}=1.350 ; 95 \% \mathrm{CI}=1.299-1.403 ; p<0.001)$, stage III $(\mathrm{OR}=1.398 ; 95 \% \mathrm{CI}=1.252-1.562 ; p<0.001)$, and stage IV $(\mathrm{OR}=2.6662 ; 95 \% \mathrm{CI}=2.221-3.095 ; p<0.001)$. Moreover, AA patients had significantly higher odds of receiving the diagnosis at autopsy $(\mathrm{OR}=2.033 ; 95 \% \mathrm{CI}=1.670-2.475 ; p<0.001)$ and being treated in Academic/Research Programs (OR=1.687; 95\% CI $=1.284-1.506 ; p<0.001)$ or Integrated Network Cancer Programs $(\mathrm{OR}=1.272 ; 95 \% \mathrm{CI}=1.133-1.427 ; p<0.001)$.

\section{Discussion}

Cutaneous melanoma is an aggressive cancer that can be deadly if not diagnosed and treated early. It has a higher incidence amongst the Caucasian population, however, in 
Table II. Tumor characteristics by race.

\begin{tabular}{|c|c|c|c|c|c|}
\hline \multirow[b]{2}{*}{ Variable } & \multicolumn{2}{|c|}{ Caucasians } & \multicolumn{2}{|c|}{ African Americans } & \multirow[b]{2}{*}{$p$-Value } \\
\hline & $\mathrm{N}$ & $\%$ & $\mathrm{~N}$ & $\%$ & \\
\hline Behavior & & & & & $<0.001$ \\
\hline In situ & 127,910 & $25.0 \%$ & 576 & $19.1 \%$ & \\
\hline Invasive & 382,937 & $75.0 \%$ & 2,432 & $80.9 \%$ & \\
\hline Breslow depth & & & & & $<0.001$ \\
\hline No mass/tumor found & 15,915 & $3.1 \%$ & 147 & $4.9 \%$ & \\
\hline $0.01-1.00 \mathrm{~mm}$ & 206,576 & $40.4 \%$ & 731 & $24.3 \%$ & \\
\hline $1.01-2.00 \mathrm{~mm}$ & 68,449 & $13.4 \%$ & 315 & $10.5 \%$ & \\
\hline $2.01-4.00 \mathrm{~mm}$ & 42,004 & $8.2 \%$ & 354 & $11.8 \%$ & \\
\hline$>4.00 \mathrm{~mm}$ & 31,918 & $6.2 \%$ & 492 & $16.4 \%$ & \\
\hline Microinvasion or unknown & 145,979 & $28.6 \%$ & 969 & $32.2 \%$ & \\
\hline Tumor's stage & & & & & $<0.001$ \\
\hline Stage 0 & 122,278 & $23.9 \%$ & 548 & $18.2 \%$ & \\
\hline Stage I & 218,213 & $42.7 \%$ & 653 & $21.7 \%$ & \\
\hline Stage II & 62,484 & $12.2 \%$ & 606 & $20.1 \%$ & \\
\hline Stage III & 40,465 & $7.9 \%$ & 457 & $15.2 \%$ & \\
\hline Stage IV & 20,948 & $4.1 \%$ & 371 & $12.3 \%$ & \\
\hline Stage unknown & 46,459 & $9.1 \%$ & 373 & $12.4 \%$ & \\
\hline Ulceration & & & & & $<0.001$ \\
\hline No ulceration & 383,832 & $75.1 \%$ & 1,613 & $53.6 \%$ & \\
\hline Ulceration present & 63,234 & $12.4 \%$ & 831 & $27.6 \%$ & \\
\hline Unknown or missing & 63,781 & $12.5 \%$ & 564 & $18.8 \%$ & \\
\hline Body region & & & & & $<0.001$ \\
\hline Head and neck & 134,017 & $26.2 \%$ & 323 & $10.7 \%$ & \\
\hline Trunk & 146,348 & $28.6 \%$ & 371 & $12.3 \%$ & \\
\hline Extremities & 207,049 & $40.5 \%$ & 1,986 & $66.0 \%$ & \\
\hline Others (Non specified, overlapping lesion of skin) & 23,433 & $4.6 \%$ & 328 & $10.9 \%$ & \\
\hline Treatment & & & & & $<0.001$ \\
\hline No treatment. Autopsy & $25,420.00$ & $5.0 \%$ & 410.00 & $13.6 \%$ & \\
\hline Receive treatment & $485,427.00$ & $95.0 \%$ & $2,598.00$ & $86.4 \%$ & \\
\hline Days to treatment $(\mathrm{SD})$ & 11.25 & 27.68 & 20.37 & 41.00 & $<0.001$ \\
\hline Days to any surgery (SD) & 10.86 & 27.05 & 19.58 & 41.02 & $<0.001$ \\
\hline Days to most effective surgery (SD) & 31.12 & 35.35 & 38.86 & 48.57 & $<0.001$ \\
\hline Days to discharge (SD) & 1.69 & 9.13 & 2.85 & 10.92 & $<0.001$ \\
\hline
\end{tabular}

$p$-Value was estimated by Chi-square or T-Test. Missing data: Days to treatment (5,6\% White; $9.7 \%$ Black); Days to any surgery (7.4\% White; $14.1 \%$ Black); Days to most effective surgery (8.7\% White; $16.7 \%$ Black); Days to discharge (17.1\% White; $24.9 \%$ Black).

rare instances, it also occurs in AA patients (1). Due to the low incidence of melanoma in AAs diagnosis and treatment is often delayed. Moreover, most public health educational campaigns target causation patients (9). Educating patients and physicians is a critical component to increasing awareness of total skin evaluations especially amongst AAs where they maybe underutilized; these have been shown to be an effective tool at detecting melanoma earlier (10).

Understanding the diversity of presentation amongst different ethnicities for melanoma is fundamental to achieving an early diagnosis and effective treatment. The significance of this study is that it contributes to understanding the demographic and socioeconomical characteristics of this disease and sheds light on treatment disparities between AAs and Caucasian patients.
Our study demonstrated that the age distribution of melanoma among AA and Caucasian patients is similar. However, there is a higher proportion of AA females compared to males; while the contrary is true for Caucasians.

Patients with a lower socioeconomic status are more likely to be diagnosed at advanced stages of melanoma and therefore have a higher mortality (11). Linos et al. studied 29,792 patients with melanoma from California and reported that patients with a lower socioeconomic status were more likely to present with a Breslow depth greater than $4 \mathrm{~mm}$ (11). A similar study by Chang et al. showed that a lower socioeconomic status was associated with a lower 5 year mortality even when stratifying for stage at diagnosis (12).

Our results showed that AAs have melanoma that is more likely to be located in the extremities compared to Caucasians 
Table III. Odds of facility type, tumor stage, behavior, ulceration, located in extremity and diagnosis at autopsy for African American patients compared to Caucasians.

\begin{tabular}{|c|c|c|c|c|}
\hline \multirow[b]{2}{*}{ Variable } & \multicolumn{4}{|c|}{$95 \% \mathrm{CI}$} \\
\hline & OR & Lower & Upper & $p$-Value \\
\hline \multicolumn{5}{|l|}{ Academic/Research program } \\
\hline AA vs. Caucasian (ref) & 1.39 & 1.284 & 1.506 & $<0.001$ \\
\hline \multicolumn{5}{|l|}{ Community cancer program } \\
\hline AA vs. Caucasian (ref) & 0.870 & 0.741 & 1.021 & 0.089 \\
\hline \multicolumn{5}{|c|}{ Comprehensive community cancer program } \\
\hline AA vs. Caucasian (ref) & 0.632 & 0.579 & 0.691 & $<0.001$ \\
\hline \multicolumn{5}{|c|}{ Integrated network cancer program } \\
\hline AA vs. Caucasian (ref) & 1.272 & 1.113 & 1.427 & $<0.001$ \\
\hline \multicolumn{5}{|l|}{ Diagnosis at autopsy } \\
\hline AA vs. Caucasian (ref) & 2.033 & 1.670 & 2.475 & $<0.001$ \\
\hline \multicolumn{5}{|l|}{ In situ } \\
\hline AA vs. Caucasian (ref) & 1.047 & 0.811 & 1.351 & 0.724 \\
\hline \multicolumn{5}{|l|}{ Invasive } \\
\hline AA vs. Caucasian (ref) & 0.955 & 0.740 & 1.233 & 0.724 \\
\hline \multicolumn{5}{|l|}{ Stage 0} \\
\hline AA vs. Caucasian (ref) & 0.965 & 0.621 & 1.498 & 0.873 \\
\hline \multicolumn{5}{|l|}{ Stage I } \\
\hline AA vs. Caucasian (ref) & 0.381 & 0.340 & 0.427 & $<0.001$ \\
\hline \multicolumn{5}{|l|}{ Stage II } \\
\hline AA $v s$. Caucasian (ref) & 1.350 & 1.299 & 1.403 & $<0.001$ \\
\hline \multicolumn{5}{|l|}{ Stage III } \\
\hline AA vs. Caucasian (ref) & 1.398 & 1.252 & 1.562 & $<0.001$ \\
\hline \multicolumn{5}{|l|}{ Stage IV } \\
\hline AA vs. Caucasian (ref) & 2.622 & 2.221 & 3.095 & $<0.001$ \\
\hline \multicolumn{5}{|l|}{ Ulceration } \\
\hline AA vs. Caucasian (ref) & 1.687 & 1.514 & 1.880 & $<0.001$ \\
\hline \multicolumn{5}{|l|}{ Location - Body's extremity } \\
\hline AA vs. Caucasian (ref) & 3.609 & 3.298 & 3.949 & $<0.001$ \\
\hline
\end{tabular}

Logistic regression models adjusted for variables related to patient demographics, tumor, and facility. AA: African American; CI: confidence interval.

that have higher distribution in the trunk, head and neck. The location of cutaneous melanoma can be significant when it comes to the initial identification and earlier diagnosis. While moles on the face and trunk may be more easily identified, acral locations can make diagnosis more challenging for physicians and patients. The location of melanoma in AAs could be a contributing factor to the delay in diagnosis. In a study conducted by Cormier et al. (13), AAs were found to have the worst prognosis when compared to white patients and other minorities (13). They also found that AAs had a 4fold higher risk of being diagnosed at stage IV disease and were $1.5 x$ more likely to die due to melanoma than white patients (13). This is congruent with our results that show that AA patients were more likely to present at advanced stages of disease when compared to white patients, even when adjusting for cofounders.

The most common and effective treatment for patients diagnosed with cutaneous melanoma is surgical resection of the lesion (14). Our results showed that AAs are less likely to receive treatment with an increased number of days to surgery. This is in concordance with the results found by Mahendraraj et al. (1), in which they found that AAs were less likely to receive surgical resection when compared to white patients (1). Moreover, a previous study that enrolled 151,154 patients diagnosed with cutaneous melanoma showed that white patients were more likely to receive appropriate surgical treatment compared to AAs $(94.5 \% \mathrm{vs}$. $86.6 \%, p<0.05)(5)$.

The authors recognize several limitations to this analysis. Due to incomplete data of the $\mathrm{NCDB}$ we were unable to include histologic subtype and tumor mitotic index. The accuracy of the data found on the database is subject to the accuracy of centers reporting. Wrong input of data can potentially confound significant associations identified. Future directions for research in melanoma are warranted to fully explore which demographic factors are associated with latestage diagnosis, considering education level, socioeconomic status, and insurance coverage as potential contributing factors. 
In conclusion, AAs have significantly higher odds of being diagnosed at a later stage of disease, ulceration, treatment delay and have melanoma located in the extremities. We hope these findings can help guide future multi-institutional studies to design diagnostic and treatment algorithms for patient-specific melanoma care and shed light on the discrepancies that exist.

\section{Conflicts of Interest}

The Authors have no conflicts of interest to declare regarding this study.

\section{Authors' Contributions}

All Authors contributed to the study design, commented on previous versions of the manuscript, read and approved the final manuscript. Material preparation, data collection and analysis were performed by DJR, ACS and AJF. The first draft of the manuscript was written by DJR and DB.

\section{Acknowledgements}

This study was supported, in part, by the Mayo Clinic Center for Individualized Medicine and Robert D. and Patricia E. Kern Center for the Science of Health Care Delivery.

\section{References}

1 Mahendraraj K, Sidhu K, Lau CS, McRoy GJ, Chamberlain RS and Smith FO: Malignant melanoma in african-americans: A population-based clinical outcomes study involving 1106 african-american patients from the surveillance, epidemiology, and end result (seer) database (1988-2011). Medicine (Baltimore) 96(15): e6258, 2017. PMID: 28403068. DOI: 10.1097/MD.0000000000006258

2 Dawes SM, Tsai S, Gittleman H, Barnholtz-Sloan JS and Bordeaux JS: Racial disparities in melanoma survival. J Am Acad Dermatol 75(5): 983-991, 2016. PMID: 27476974. DOI: 10.1016/j.jaad.2016.06.006

3 Stubblefield $\mathrm{J}$ and Kelly B: Melanoma in non-caucasian populations. Surg Clin North Am 94(5): 1115-1126, ix, 2014. PMID: 25245971. DOI: 10.1016/j.suc.2014.07.008

4 Kaufman BP and Alexis AF: Skin cancer mortality in patients with skin of color. Cutis 99(5): 307-308, 2017. PMID: 28632798.
5 Collins KK, Fields RC, Baptiste D, Liu Y, Moley J and Jeffe DB: Racial differences in survival after surgical treatment for melanoma. Ann Surg Oncol 18(10): 2925-2936, 2011. PMID: 21479687. DOI: $10.1245 / \mathrm{s} 10434-011-1706-3$

6 Harvey VM, Patel H, Sandhu S, Wallington SF and Hinds G: Social determinants of racial and ethnic disparities in cutaneous melanoma outcomes. Cancer Control 21(4): 343-349, 2014. PMID: 25310216. DOI: 10.1177/107327481402100411

7 Razdan SN, Cordeiro PG, Albornoz CR, Disa JJ, Panchal HJ, Ho $\mathrm{AY}$, Momoh AO and Matros E: National breast reconstruction utilization in the setting of postmastectomy radiotherapy. J Reconstr Microsurg 33(5): 312-317, 2017. PMID: 28235218. DOI: $10.1055 / \mathrm{s}-0037-1598201$

8 Bilimoria KY, Stewart AK, Winchester DP and Ko CY: The national cancer data base: A powerful initiative to improve cancer care in the united states. Ann Surg Oncol 15(3): 683-690, 2008. PMID: 18183467. DOI: $10.1245 / \mathrm{s} 10434-007-9747-3$

9 Byrd KM, Wilson DC, Hoyler SS and Peck GL: Advanced presentation of melanoma in african americans. J Am Acad Dermatol 50(1): 21-24; discussion 142-143, 2004. PMID: 14699360. DOI: 10.1016/s0190-9622(03)02091-7

10 Whited JD and Grichnik JM: The rational clinical examination. Does this patient have a mole or a melanoma? JAMA 279(9): 696-701, 1998. PMID: 9496989. DOI: 10.1001/jama.279.9.696

11 Linos E, Swetter SM, Cockburn MG, Colditz GA and Clarke CA: Increasing burden of melanoma in the united states. J Invest Dermatol 129(7): 1666-1674, 2009. PMID: 19131946. DOI: $10.1038 /$ jid.2008.423

12 Chang AE, Karnell LH and Menck HR: The national cancer data base report on cutaneous and noncutaneous melanoma: A summary of 84,836 cases from the past decade. The american college of surgeons commission on cancer and the american cancer society. Cancer 83(8): 1664-1678, 1998. PMID: 9781962. DOI: 10.1002/ (sici)1097-0142(19981015)83:8<1664::aid-cncr23>3.0.co;2-g

13 Cormier JN, Xing Y, Ding M, Lee JE, Mansfield PF, Gershenwald JE, Ross MI and Du XL: Ethnic differences among patients with cutaneous melanoma. Arch Intern Med 166(17): 1907-1914, 2006. PMID: 17000949. DOI: 10.1001/archinte.166.17.1907

14 Harlan LC, Lynch CF, Ballard-Barbash R and Zeruto C: Trends in the treatment and survival for local and regional cutaneous melanoma in a us population-based study. Melanoma Res 21(6): 547-554, 2011. PMID: 21897302. DOI: 10.1097/CMR.0b013 e32834b58e4

Received October 9, 2019

Revised October 23, 2019 Accepted October 24, 2019 